\title{
In vitro and in vivo inhibitory effect of three Cox-2 inhibitors and epithelial-to-mesenchymal transition in human bladder
} cancer cell lines

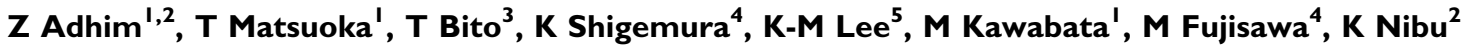 \\ and T Shirakawa ${ }^{*, 1,4}$
}

'Division of Infectious Disease Control, Center for Infectious Disease, Kobe University Graduate School of Medicine, 7-5-I, Kusunoki-cho, Chuo-ku, Kobe 650-00 I 7, Japan; ' ${ }^{2}$ Department of Otolaryngology Head and Neck Surgery, Kobe University, Graduate School of Medicine, Kobe, Japan; ${ }^{3}$ Department of Clinical Molecular Medicine, Kobe University Graduate School of Medicine; ${ }^{4}$ Division of Urology, Department of Organs Therapeutics, Kobe University Graduate School of Medicine, Kobe, Japan; ${ }^{5}$ Department of Biochemistry, Korea University College of Medicine, Seoul, Republic of Korea

BACKGROUND: Although the anti-tumour effect of cyclooxygenase-2 (Cox-2) inhibitors in invasive bladder cancer has been confirmed, its mechanisms of action are unclear. Recently, the concept of an epithelial-to-mesenchymal transition (EMT) promoting carcinoma progression has been suggested, and a key feature of the EMT is the downregulation of E-cadherin. In this study, we investigated the effect of Cox-2 inhibitors on reversal EMT and tumour growth inhibition in bladder cancer cells.

METHODS: We used three Cox-2 inhibitors, etodolac, celecoxib and NS-398 and three human bladder cancer cell lines, T24, 5637 and KK47, in this study. T24 xenograft tumour mouse model was used in the in vivo study.

RESULTS: Within the clinical drug concentrations, only etodolac showed the in vitro growth inhibition in T24 not in the other cell lines. Etodolac reduced SNAIL mRNA and vimentin cell surface expression, and induced E-cadherin mRNA and E-cadherin cell surface expression, in T24. Etodolac also most strongly inhibited the cell migration of T24 in vitro and showed the highest tumour growth inhibition in T24 tumour in vivo.

CONCLUSION: Etodolac at clinical doses exhibited induced in vitro and in vivo anti-tumour effects and reversal effect of EMT in T24. These results suggest that etodolac is a good candidate for an anti-tumour or chemopreventive reagent for high-grade bladder cancer.

British Journal of Cancer (201 I) 1 05, 393-402. doi:10.1038/bjc.201 I.262 www.bjcancer.com

Published online 12 July 2011

(c) 201। Cancer Research UK

Keywords: Cox-2 inhibitor; E-cadherin; SNAIL; EMT; bladder cancer

Bladder cancer, transitional cell carcinoma (TCC) of the urinary bladder, accounts for approximately $4.6 \%$ of all malignant tumour (Jemal et al, 2007). Although most cases of bladder cancer present as a superficial tumour, and are treated with transuretheral resection of the bladder tumour (TUR-BT), the recurrence rate after TUR-BT is high $(30-85 \%)$ and approximately $10-30 \%$ of cases will progress to a muscle-invasive tumour that has a poorer prognosis (Pasin et al, 2008). Therefore, an effective strategy for preventing the progression of bladder cancer is clearly needed. Cyclooxygenase-2 (Cox-2) is overexpressed in high-grade invasive TCC, and the anti-tumour effect of Cox- 2 inhibitors in invasive TCC of urinary bladder has been suggested in both pre-clinical and clinical studies (Okamoto et al, 2008; Parada et al, 2009; Qin et al, 2009; Dhawan et al, 2010). However, the mechanism of action for the anti-tumour effects of Cox-2 inhibitors is unclear.

Previously, we have reported that etodolac, a selective Cox-2 inhibitor, induced upregulation of E-cadherin and an in vivo

*Correspondence: Dr T Shirakawa; E-mail: toshiro@med.kobe-u.ac.jp Revised 23 March 201 I; accepted 21 June 201 I; published online 12 July 2011 growth inhibitory effect in high-grade human bladder cancer cell line T24 (Okamoto et al, 2008). E-cadherin, which is an epithelial cell adhesion molecule, is highly associated with tumour invasiveness, metastatic dissemination and poor prognosis (Guarino et al, 2007). There is a growing body of evidence suggesting that loss of E-cadherin expression or mutation in the E-cadherin gene may have a pivotal role in tumour progression as marked by increased mobility and invasiveness in various types of cancers, including bladder cancer (Birchmeier and Behrens, 1994; Imao et al, 1999).

Epithelial-to-mesenchymal transition (EMT) is the process by which epithelial cells dramatically alter their shape and motile behaviour as they differentiate into mesenchymal cells (Mendez et al, 2011). The most well-known familiar change that occurs during EMT is downregulation of surface E-cadherin expression, resulting in the loss of homotypic adhesion. During EMT, carcinoma cells become more motile, invasive and resistant to apoptosis by acquiring characteristics similar to embryonic mesenchymal cells, thereby allowing penetration of the stroma surrounding the initial neoplastic focus (Guarino et al, 2007). In contrast to E-cadherin, the epithelial marker of EMT, Zeb-1, Zeb-2 and vimentin are widely known as the mesenchymal markers of EMT (Sanchez-Tillo et al, 2010). McConkey et al (2009) measured 
these EMT markers in a panel of 20 human urothelial TCC cell lines and a set of 114 primary urothelial tumours, and observed a strong inverse correlation between the expression of E-cadherin and those of Zeb-1, Zeb-2 and vimentin. They found that the expression of the mesenchymal markers was confined to the muscle-invasive tumour. In addition, several previous studies have suggested that EMT was associated with bladder cancer progression and metastasis (Chaffer et al, 2006; McConkey et al, 2009; Kenney et al, 2011; Wiklund et al, 2011).

Both Cox-2 overexpression and the loss of E-cadherin expression are frequently detected in invasive bladder cancer (Shariat et al, 2001). Cox-2 and prostaglandin E2 expression have been associated with a significant reduction in E-cadherin and promotion of EMT via SNAIL, Zeb-1, Slug, Twist and other transcriptional factor-mediated mechanisms (Morgillo et al, 2007). In this study, we evaluated the in vitro and in vivo growth inhibitory effects of three different Cox-2 inhibitors, etodolac, celecoxib and NS-398 on three human bladder cancer cell lines, T24, 5637 and KK47, and we examined whether Cox-2 inhibitors could reverse the EMT in order to identify the mechanism of action for Cox-2 inhibitors as anti-tumour agents.

\section{MATERIAL AND METHODS}

\section{Cells and cell culture}

The human urinary bladder cancer cell lines T24 (Bubenik et al, 1973) and 5637 (Fogh, 1978) were purchased from the American Type Culture Collection (Manassas, VA, USA); KK47 (Kotoh et al, 1997) was generously provided by Dr Naito (Kyushu University, Fukuoka, Japan). All cell lines were cultured in RPMI (Roswell Park Memorial Institute) 1640 medium (Gibco, Grand Island, NY, USA) supplemented with $10 \%$ fetal bovine serum, at $37^{\circ} \mathrm{C}$ with $5 \%$ carbon dioxide.

\section{In vitro cytotoxicity assay}

The T24, 5637 and KK47 cells were seeded at a density of 500 per well in 96-well tissue culture plates. The etodolac was obtained from Nippon Shinyaku (Tokyo, Japan) and dissolved by dimethyl sulphoxide (DMSO; Sigma Chemical, St Louis, MO, USA). The celecoxib (4-(3-methyl-5-(4-methylphenyl)-1H-pyrazol-1-yl) benzenesulfonamide) was obtained from Key Organics (Camelford, UK) and NS-398 was obtained from Cayman Medical Company (Ann Arbor, MI, USA). All drugs were dissolved by DMSO. After $24 \mathrm{~h}$ of incubation, the cells were treated with etodolac, celecoxib and NS-398 at several concentration (at $10^{-4}, 10^{-5}, 10^{-6}$ or $10^{-7} \mathrm{M}$ ); the same volume of DMSO without a drug served as a control. The cell number was assessed at 2, 4 and 6 days after the initiation of drug treatment. The alamar blue assay was performed with a fluorimetric method according to the procedure described before (Ahmed et al, 1994). To determine the number of cells, the emitted fluorescence was compared with a standard curve from a known number of cells.

\section{Reverse transcriptase - PCR of mRNA expressions of Cox-2 and EMT-related markers}

The cells were treated with $10^{-5} \mathrm{M}$ concentrations of etodolac, celecoxib, NS-398 or DMSO (control) for $24 \mathrm{~h}$, and then the cell pellets $\left(5-10 \times 10^{-6}\right)$ were collected. Total RNA was extracted from each group using Trizol (Invitrogen, Carlsbad, CA, USA). The extracted mRNA was reverse transcribed using the Taq-Man Reverse Transcription Reagents kit (Applied Biosystems, Foster City, CA, USA). Real-time quantitative PCR using the SYBR Green I dye fluoresces system (Applied Biosystems) was performed for the relative quantification of the mRNA expression according to a previously described method (Guo et al, 2006). The sequences for the primers were as follows: Cox-2, forward: 5'-TGGACAGGGAGG
ATTTTGAG-3', reverse: $5^{\prime}$-AGGCTGTGCCTTCCTACAGA-3'; E-cadherin, forward: $5^{\prime}$-ACGTCGTAATCACCACACTGA-3', reverse: $5^{\prime}$-TTCGTCACTGCTACGTGTAGAA-3'; Cytokeratin 19, forward: 5'-GCGGGACAAGATTCTTGGTG-3', reverse: $5^{\prime}$-CTTCAGGCCTTC GATCTGCAT-3'; Vimentin, forward: 5'-CTTCGCCAACTACATC GACA-3', reverse: $5^{\prime}$-GCTTCAACGGCAAAGTTCTC- ${ }^{\prime}$; $N$-cadherin, forward: $5^{\prime}$-ACAGTGGCCACCTACAAAGG-3', reverse: $5^{\prime}$-CCGAG ATGGGGTTGATAATG-3'; SNAIL, forward: 5-TCGTCCTTCTCCT CTACTTC-3', reverse: 5-TTCCTTGTTGCAGTATTTGC-3'; Slug, forward: $5^{\prime}$-TCGGACCCACACATTACC- $3^{\prime}$, reverse: $5^{\prime}$-CCGAGAT GGGGTTGATAATG-3'; Twist, forward: $5^{\prime}$-AGCTGAGCAAGATT CAGACCCTC-3', reverse: 5'-CCGTCTGGGAATCACTGT C-3'; Zeb 1, forward: $5^{\prime}$-CTGAAGAGGACCAGAGGCAG-3', reverse: $5^{\prime}$-CCCAG AACTGCGTCACATGTC- $3^{\prime}$; and $\beta$-actin, forward: $5^{\prime}$-GGACTTCGA GCAAGAGATGG-3', reverse: 5-AGCACTGTGTTGGCGTACAG-3'. The PCR reactions were performed in the ABI7700 (Applied Biosystems) with PCR profiles as follows: 1 cycle for $5 \mathrm{~min}$ at $95^{\circ} \mathrm{C}$, 45 cycles for $30 \mathrm{~s}$ at $94^{\circ} \mathrm{C}, 30 \mathrm{~s}$ at $56^{\circ} \mathrm{C}, 1 \mathrm{~min}$ at $72^{\circ} \mathrm{C}$ and with final cooling to $40^{\circ} \mathrm{C}$. The values of $\beta$-actin mRNA were used as an endogenous control to normalise for differences in the amount of total RNA.

\section{Flow cytometric analysis of E-cadherin and vimentin expression}

E-cadherin and vimentin expression in three different cell lines, treated with etodolac, celecoxib or NS-398 at $10^{-5} \mathrm{M}$ or DMSO alone for $36 \mathrm{~h}$. Cells were harvested by a short trypsinization of confluent monolayers. Cell suspensions were made in phosphatebuffered saline (PBS) at a concentration of $10^{6} \mathrm{cells}^{-1}$. They were blocked by incubating the cell suspension with $1 \mu \mathrm{g}$ of Affinity Purified anti-mouse CD16/32 - blocks Fc binding (eBioscience Inc., San Diego, CA, USA) for $10 \mathrm{~min}$, followed by normal mouse IgG 1 (Santa Cruz Biotechnology Inc., Santa Cruz, CA, USA) as a negative control and $1 \mu \mathrm{g}$ of E-cadherin unconjugated primary antibodies (Santa Cruz Biotechnology Inc.) per $100 \mu \mathrm{l}$ of the prepared cell suspension (equivalent to one million cells) at $4{ }^{\circ} \mathrm{C}$ for $30 \mathrm{~min}$. To wash off excess antibody following staining, we added $2 \mathrm{ml}$ of $1 \times \mathrm{PBS}$ to each tube, centrifuged them for $5 \mathrm{~min}$ at 2000 r.p.m., and aspirated the supernatant. The cell suspension was incubated in Alexa Fluor 647 goat anti-mouse IgG (Invitrogen) at $4{ }^{\circ} \mathrm{C}$ for $30 \mathrm{~min}$, washed with PBS and fixed in $2 \%$ paraformaldehyde. For the vimentin expression analysis, we used vimentin-conjugated FITC primary antibodies (Santa Cruz Biotechnology Inc.), and performed the cell permeabilisation before analysis. Data acquisition and analysis were performed on duplicate samples on a FACScan flow cytometer (FCM) using CELLQuest software (Becton Dickinson, San Jose, CA, USA).

\section{Immunocytofluorescence staining}

T24 cell lines for immunocytofluorescence staining of E-cadherin and vimentin were plated on glass coverslips in four-well culture dishes and treated with $10^{-5} \mathrm{M}$ concentrations of etodolac, celecoxib, NS-398 or DMSO. At $72 \mathrm{~h}$ after the initiation of drug treatment, were washed with PBS three times and fixed with cold methanol for $10 \mathrm{~min}$ on ice and permeabilised in $0.5 \%$ Triton $\mathrm{X}-100 / \mathrm{PBS}$ for $5 \mathrm{~min}$ at room temperature. After washing with PBS for $5 \mathrm{~min}$ (three times), cells were blocked with normal goat serum $10 \%$ for $30 \mathrm{~min}$ at room temperature, and then incubated with the specific primary antibodies. The following primary antibodies were used for immunostaining: E-cadherin unconjugated primary antibodies (Santa Cruz Biotechnology Inc.) at 1:200 dilution in PBS and vimentin conjugated FITC primary antibodies (Santa Cruz Biotechnology Inc.) at $1: 100$ dilution in PBS. Alexa fluor-647 (Invitrogen) conjugated secondary antibodies for E-cadherin were used. Cells were co-stained with 4',6-diamidino-2-phenylindole 
(Molecular Probes, Eugene, OR, USA) at 1:500 dilution in PBS, to visualise the nuclei. Stained cells were mounted with fluorescent mounting medium (Dako, Carpinteria, CA, USA). The fluorescent images were obtained by confocal laser scanning microscope (LSM 700; Carl Zeiss Meditec, Göttingen, Germany).

\section{Wound healing assay}

We assessed cell migration by determining the ability of the cells to move into an acellular space in a two-dimensional in vitro wound healing assay. Confluent cell monolayers were wounded by manually scraping the cells with a pipette tip. Debris was removed from the culture by washing twice with PBS. After that the cells were incubated with medium including FBS $10 \%$ and drug (etodolac, celecoxib, NS-398 at $10^{-5} \mathrm{M}$ or DMSO as the control). Images were acquired immediately at $0 \mathrm{~h}$ (baseline control) and at $24 \mathrm{~h}$ using a BIOREVO BZ-9000 microscope (Keyence, Osaka, Japan). The wound area without cells was calculated using VH software Keyence (Keyence), and we then compared the total wound area without cells after $24 \mathrm{~h}$ of exposure of each drug.

\section{Animal experiments}

In all, 24 athymic BALB/c (nu/nu) mice (5 weeks old) were purchased from Charles River Japan (Yokohama, Japan). T24 cells $\left(5.0 \times 10^{6}\right)$ suspended in $250 \mu$ lof RPMI 1640 mixed with $250 \mu \mathrm{l} \mathrm{BD}$ Matrigel (Becton Dickinson, Franklin Lakes, NJ, USA) were transplanted to the backs of these mice. At 14 days after tumour inoculation, the T24 animals were randomly assigned to four experimental groups of six animal each as follows: group 1, PBS ( + DMSO) treatment control group (six animals); group 2, etodolac-treatment group; group 3, celecoxib-treatment group; group 4, NS-398-treatment group. Beginning at 14 days after tumour inoculation, the tumour size was measured every other day and was calculated using the following formula: volume (a rotational ellipsoid) $=\mathrm{M} 1 \times \mathrm{M}^{2} \times 0.5236$, where $\mathrm{M} 1=$ the long axis and $\mathrm{M} 2=$ the short axis. These mice were intraperitoneally injected with etodolac ( $10 \mathrm{mg} \mathrm{kg}^{-1}$ body weight per day), celecoxib (10 $\mathrm{mg} \mathrm{kg}^{-1}$ body weight per day), NS-398 ( $10 \mathrm{mg} \mathrm{kg}^{-1}$ body weight per day) or PBS + DMSO using the same volume as with the drugs daily for 4 weeks, using a microliter syringe fitted with a 28 -gauge needle. The tumours were extracted at 4 weeks after treatment initiation for apoptosis analysis. All procedures involving the mice were approved by the Institutional Animal Care and Use Committee (Permission No. P070802), and performed according to the Guidelines of Animal Experimentation of Kobe University.

\section{TUNEL assay}

The TUNEL assay (Takara Bio Inc., Shiga, Japan) method uses terminal deoxynucleotidyl transferase to label the $3^{\prime}-\mathrm{OH}$ ends of DNA fragments that are generated during the process of apoptosis. The cells undergoing apoptosis are specifically labelled with fluorescein-dUTP with high sensitivity, allowing their immediate detection by viewing with a BIOREVO BZ-9000 fluorescence microscope (Keyence).

To quantitate apoptotic-positive cells per eight random slide was estimated by processing $\times 80$ images using Image $\mathrm{J} 1.41$ software (National Institutes of Health, Bethesda, MD, USA). Apoptotic index was standardised by that of control group being as 1 and expressed as the arbitrary unit.

\section{Statistical analysis}

Determination of statistical significance was performed using a $t$-test for direct two group comparisons and analysis of variance for multiple group comparisons. All data are reported as s.d. is an index of the variability of the original data points and reported as \pm s.e.m. if the study were repeated of three independent experiments. Statistical significance was set at $P<0.05$.

\section{RESULTS}

Celecoxib and NS-398 inhibited the cell growth of all the three cell lines, but etodolac inhibited only growth of only T24 and 5637

The three human bladder cancer cell lines; T24, 5637 and KK47, originated from tumours of three different histological grades: III, II and I (Bubenik et al, 1973; Kotoh et al, 1997). The significant cell growth inhibitory effect compared with control $(0 \mathrm{M})$ was observed in T24 cells with $10^{-4}-10^{-5} \mathrm{M}$ of etodolac and celecoxib, and $10^{-4} \mathrm{M}$ of NS-398, in 5637 cells with $10^{4} \mathrm{M}$ of etodolac, and $10^{-4}-10^{-5} \mathrm{M}$ of celecoxib and NS-398, and in KK47 cells with $10^{-4}-10^{-5} \mathrm{M}$ of celecoxib and $10^{-5} \mathrm{M}$ of NS-398 (Figure $1 \mathrm{G}-\mathrm{I}$ ).

T24 cells expressed the lowest level of E-cadherin and cytokeratin, and the highest level of Cox-2, vimentin and transcriptional factors (SNAIL, Slug, Twist and Zeb 1) among the three cell lines

To characterise the EMT features of the three cell lines, we compared the mRNA expressions of Cox-2, epithelial markers (E-cadherin, Cytokeratin), mesenchymal markers (Vimentin, $N$-cadherin) and transcriptional factors (SNAIL, Slug, Twist and Zeb-1), which are key signal factors of EMT in each cell line. Consistent with previous studies, we found that T24 cells originating from the highest grade III TCC expressed the lowest level of E-Cadherin and Cytokeratin, and the highest level of Cox-2, Vimentin and EMT-transcriptional factors (SNAIL, Slug, Twist and Zeb 1) mRNA among the three human bladder cancer cell lines (Figure 2). In addition, we found an inverse correlation between epithelial markers and mesenchymal markers and transcriptional factors mRNA expressions, that is, the lowest E-cadherin and the highest Vimentin and SNAIL were found in T24 cells and the highest E-cadherin and the lowest Vimentin and SNAIL were found in 5637 cells (Figure 2). These findings suggest the strongest EMT features in the T24 cell line.

Cox-2 inhibitors enhanced mRNA expressions of epithelial markers and suppressed mRNA expressions of mesenchymal markers and EMT transcriptional factors in all the three cell lines

To investigate the effect of Cox-2 inhibitors on EMT in three human bladder cancer cell lines, we examined the mRNA expressions of epithelial markers (E-cadherin and Cytokeratin), mesenchymal markers (Vimentin and $N$-cadherin) and EMTtranscriptional factors (SNAIL, Slug, Twist and Zeb 1) in the cell lines with or without Cox-2 inhibitors. Etodolac significantly enhanced E-cadherin mRNA in the T24 and KK47 cell lines, Cytokeratin in all three cell lines; celecoxib significantly enhanced E-cadherin and Cytokeratin mRNA in all three cell lines; and NS398 enhanced E-cadherin mRNA in the T24 and 5637 cell line, Cytokeratin in all three cell lines. In the T24 cell line, etodolac induced the highest expression of E-cadherin mRNA compared with the other Cox-2 inhibitors (Figure 3A). All Cox-2 inhibitors significantly suppressed the mRNA expression of mesenchymal markers and EMT transcriptional factors.

Etodolac most strongly induced E-cadherin expression and reduced vimentin expression on the T24 cell surface

We also examined the cell surface markers of EMT: E-cadherin as an epithelial marker and vimentin as a mesenchymal marker. 
A

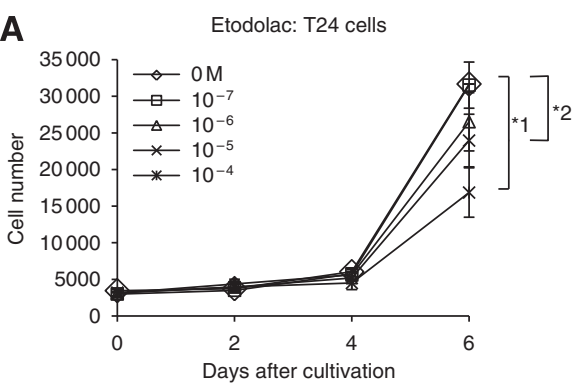

\section{D}
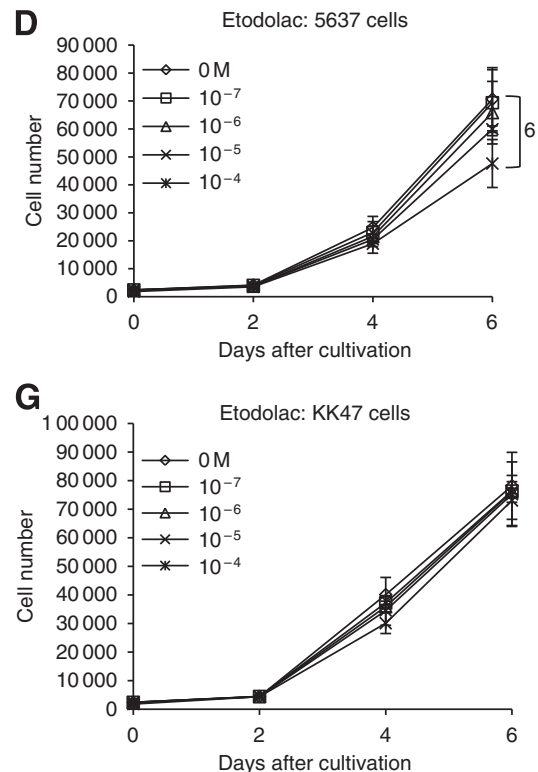

$B$

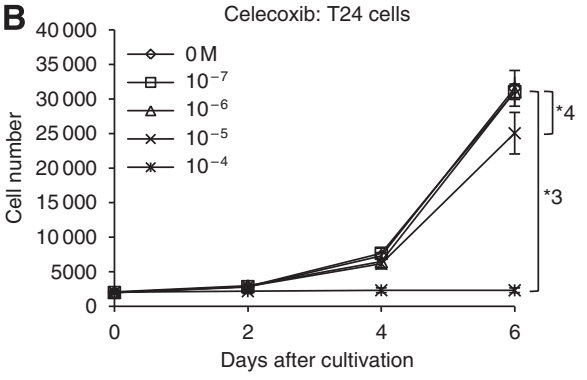

E

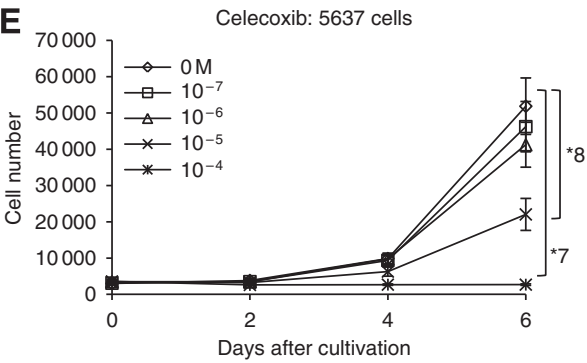

H

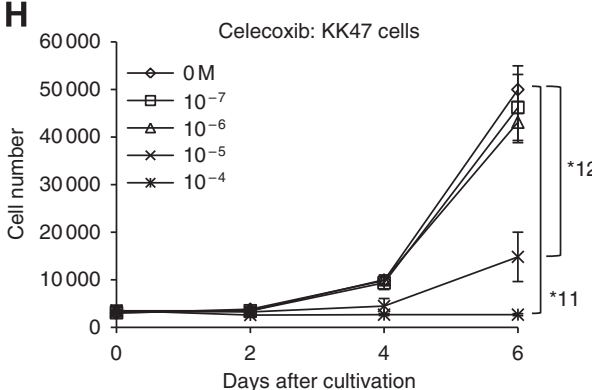

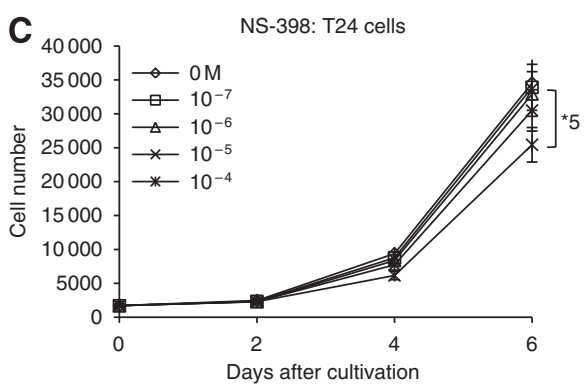

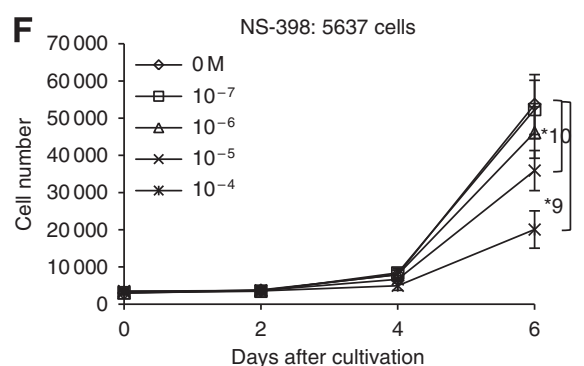

I

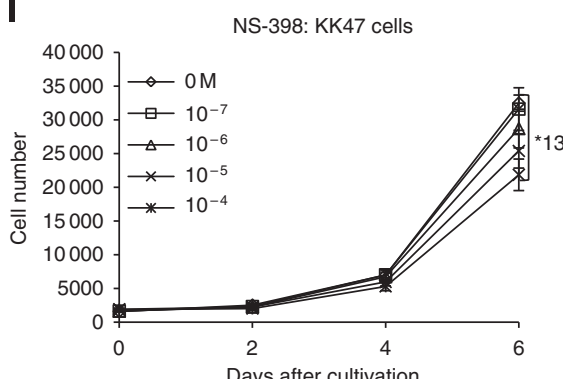

Figure I In vitro cytotoxicity in T24 (A-C), 5637 (D-F) and KK47 (G-I) cell lines treated with etodolac, celecoxib and NS-398. All significant differences at day 6 were marked with asterisks $(*) \mid-13$. Each point represents triplicate averages, with \pm s.e.m. bars. $* \mid, P=0.008 ; * 2, P<0.005$;

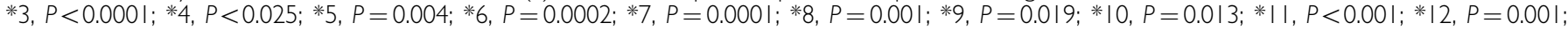
$*|3, P<0.000|$.

We calculated the changes in the ratio of E-cadherin or vimentin expressed cells: $A-B / B: A=$ marker expressed cell number with Cox-2 inhibitors, $B=$ marker expressed cell number without Cox-2 inhibitors. In the T24 cell line, etodolac most strongly increased Ecadherin cell surface expression $(+21.62 \%)$ and decreased vimentin cell-surface expression ( $-20.19 \%$; Figure $4 \mathrm{~A}$ and D). In the 5637 cell line, NS-398 most strongly increased E-cadherin cell surface expression $(+17.45 \%)$ and decreased vimentin cell surface expression (-18.98\%; Figure 4B and E). In the KK47 cell line, celecoxib most strongly increased E-cadherin cell surface expression $(+14.43 \%)$ and decreased vimentin cell surface expression (-14.73\%; Figure 4C and F). Interestingly, the Cox-2 inhibitor that most strongly decreased vimentin most strongly increased E-cadherin in all cell lines. In addition, the greatest increase in the ratio of E-cadherin expression and the greatest decrease in the ratio of vimentin expression were induced by etodolac in the T24 cell line.

\section{Etodolac and celecoxib but not NS-398 induced the mesenchymal-to-epithelial (MET) transition type changes in T24 cells}

An inverse correlation between E-cadherin and vimentin was observed across the treatment groups. Vimentin staining was observed in cytoskeletal lesion of control and NS-398-treated cells (Figure 5C and D), but not in that of etodolac- and celecoxibtreated cells (Figure 5A and B). Etodolac and celecoxib induced E-cadherin expressions in cell surfaces (intercellular membrane) of T24 cells (Figure 5A and B). In addition, although control and
NS-398-treated cells showed the mesenchymal features of cell appearance with losing cell-cell contact and an elongated phenotype (Figure 5C and D), etodolac- and celecoxib-treated cells showed the characteristic 'cobblestone' appearance of epithelial cells (Figure 5A and B).

\section{Etodolac suppressed cell migration in T24 cell line}

The T24 cell line was isolated from the highest histological grade III tumour, and expressed the lowest level of E-cadherin among the three bladder cancer cell lines used in this study. Cells that undergo EMT shows enhanced cell migration as a mesenchymal feature. To investigate the effect of Cox-2 inhibitors on the cell migration of T24 cells, we performed an in vitro wound healing assay, which is commonly used for assessing the effect of pro- and anti-migratory agents on culturing cells (Raftopoulou et al, 2004). As shown in Figure $6 \mathrm{~A}, 24 \mathrm{~h}$ after creating the wound, T-24 cells treated with Cox-2 inhibitors migrated slower than the control cells. The highest inhibition of cell migration was observed in the cells treated with etodolac after $24 \mathrm{~h}$ (Figure 6B).

\section{Etodolac significantly suppressed T24 tumour growth in vivo}

We examined the in vivo growth inhibitory effect of Cox-2 inhibitors on subcutaneous tumours of the most invasive T24 cell line. Although the in vitro study showed that celecoxib had a higher inhibitory effect on T24 cell growth than did etodolac, the in vivo study showed that etodolac most highly inhibited the T24 tumour growth among the three Cox-2 inhibitors (Figure 7A). 
A

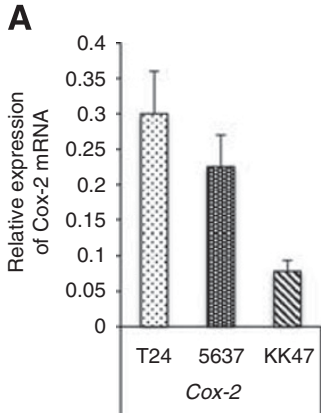

B

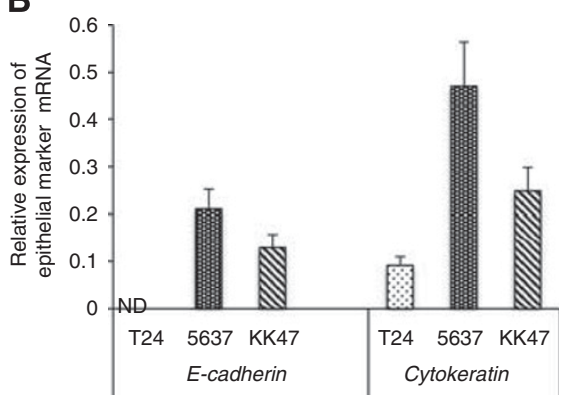

C

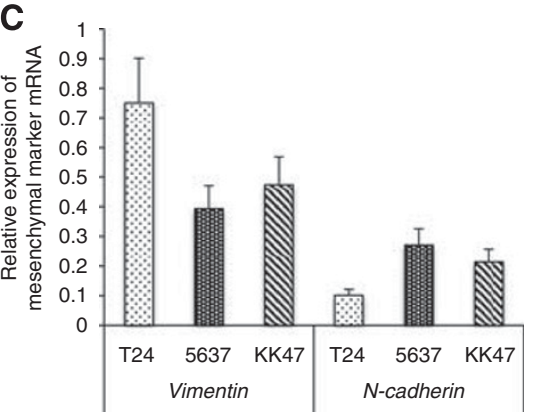

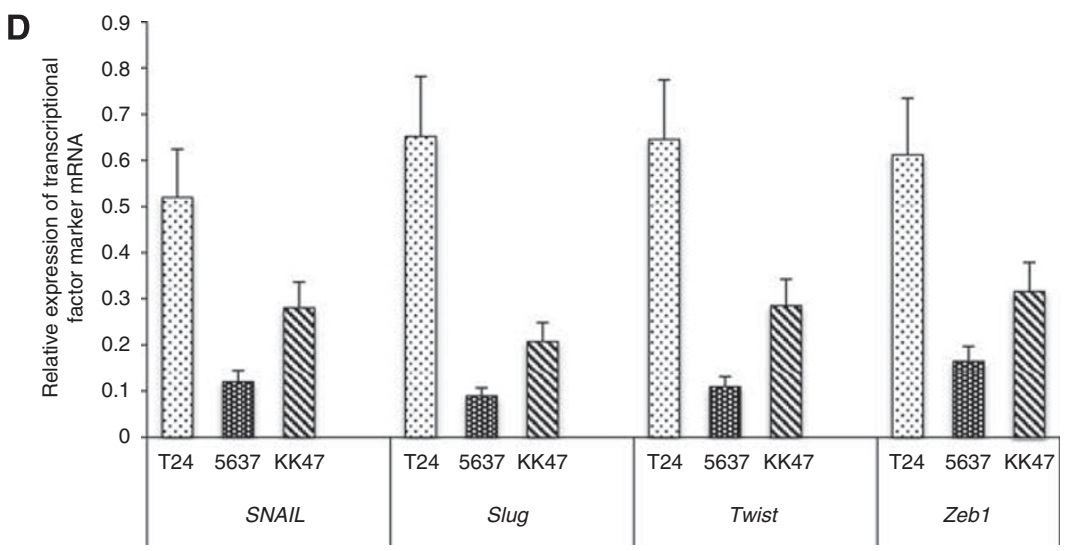

Figure 2 Relative mRNA levels of (A) Cox-2, (B) epithelial marker (E-cadherin and Cytokeratin) (C) mesenchymal marker (Vimentin and N-cadherin) and (D) transcriptional factor (SNAIL, slug, twist and Zeb /) in the three bladder cancer cell lines. T24 cells expressed the highest Cox-2, lowest E-cadherin and cytokeratin, highest Cox-2, vimentin and transcriptional factor (SNAIL, slug, twist and Zeb I) mRNA among three cell lines. Each point represent triplicate averages with \pm s.e.m. bars. $\beta$-Actin was used as the endogenous RNA control to normalise for differences in the amount of total RNA.
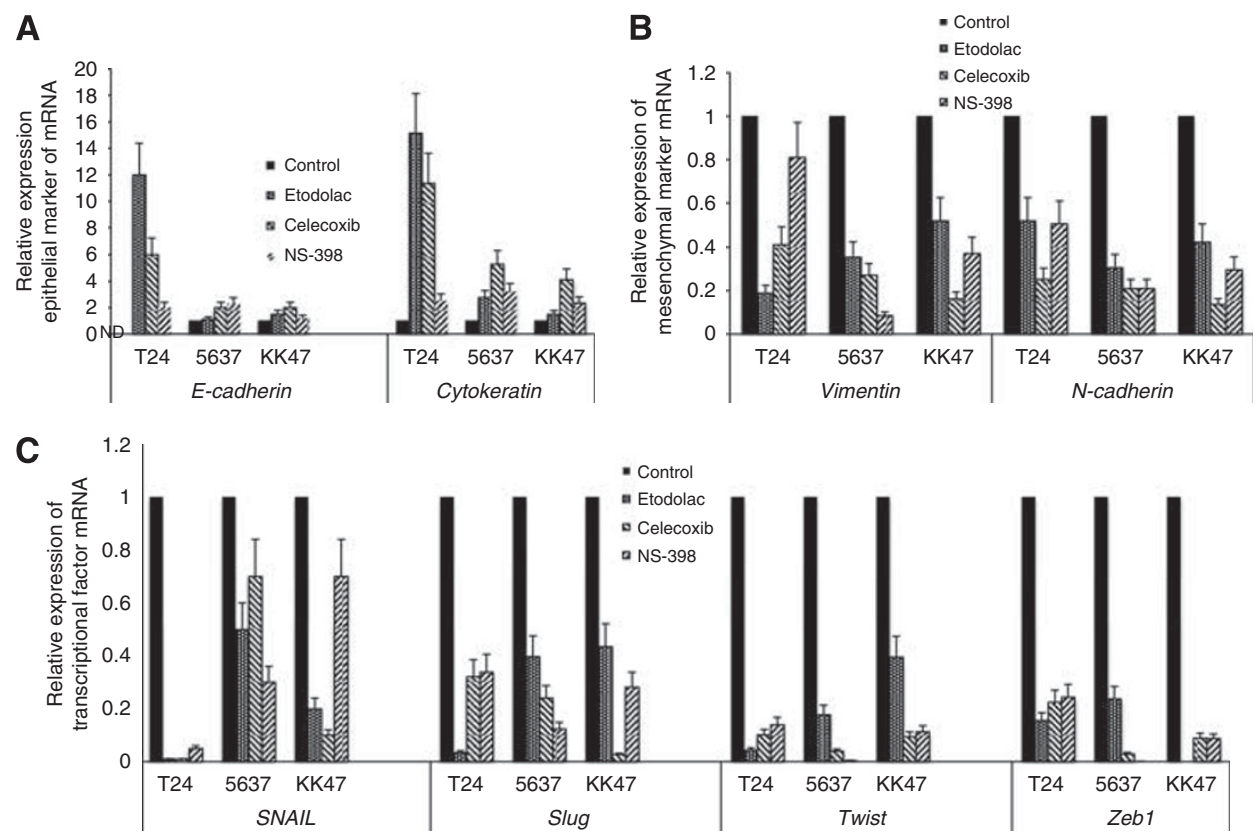

Figure 3 Relative mRNA levels of epithelial marker (E-cadherin and cytokeratin) (A), mesenchymal marker (vimentin and N-cadherin) (B), and transcriptional factor (SNAIL, slug, twist and Zeb I) (C) in T24, 5637 and KK47 with or without Cox-2 inhibitors at 10 $0^{5}$ M. Each point represent triplicate averages, with \pm s.e.m. bars. $\beta$-Actin was used as the endogenous RNA control to normalise for differences in the amount of total RNA.

\section{Cox-2 inhibitors induced cell apoptosis in T24 tumour in vivo}

One of the mesenchymal features of the cells undergoing EMT is the acquisition of resistance to cell apoptosis. To investigate whether Cox-2 inhibitors could induce cell apoptosis, we perform a TUNEL staining assay for T24 tumour specimens isolated from the in vivo study. As shown in Figure 7B, in all group, significantly increased of apoptotic index was observed along etodolac group with celecoxib, NS-398 and control group $(P=0.03, P=0.001$, 
A
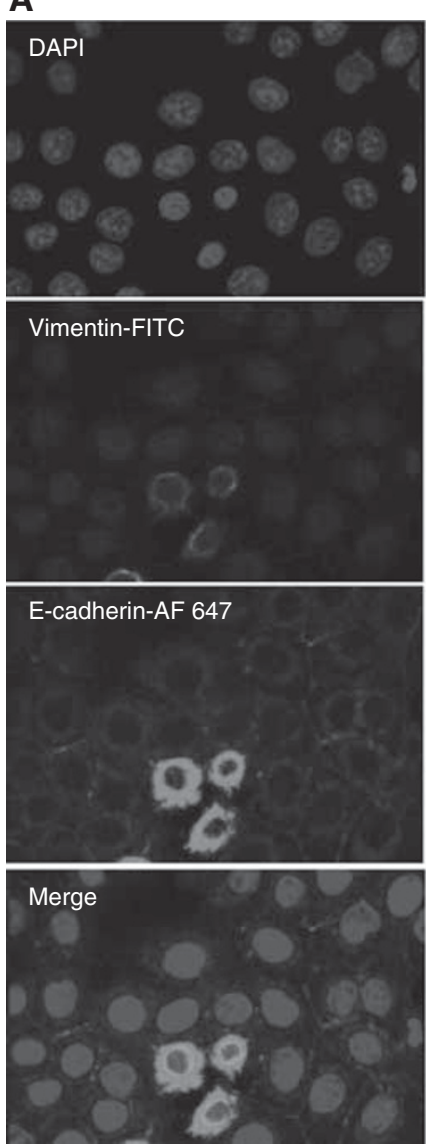

Etodolac
B
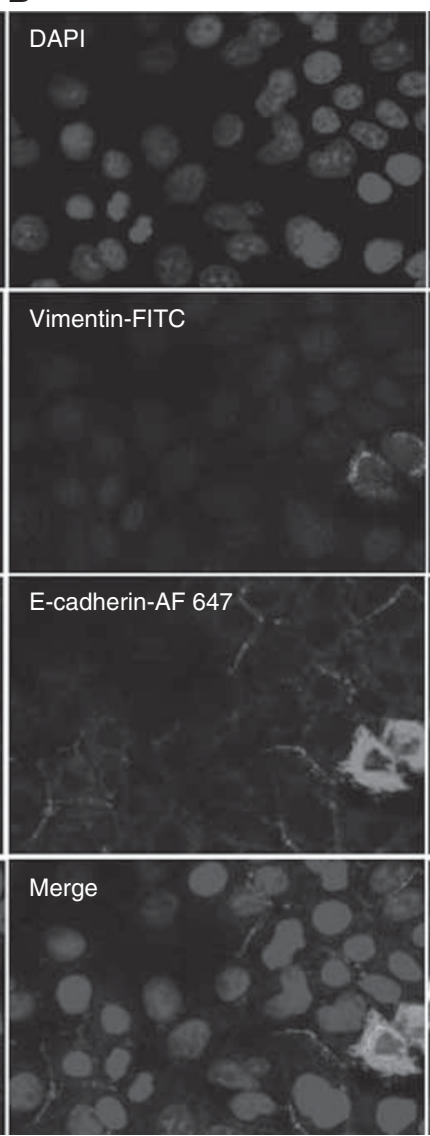

Celecoxib
C
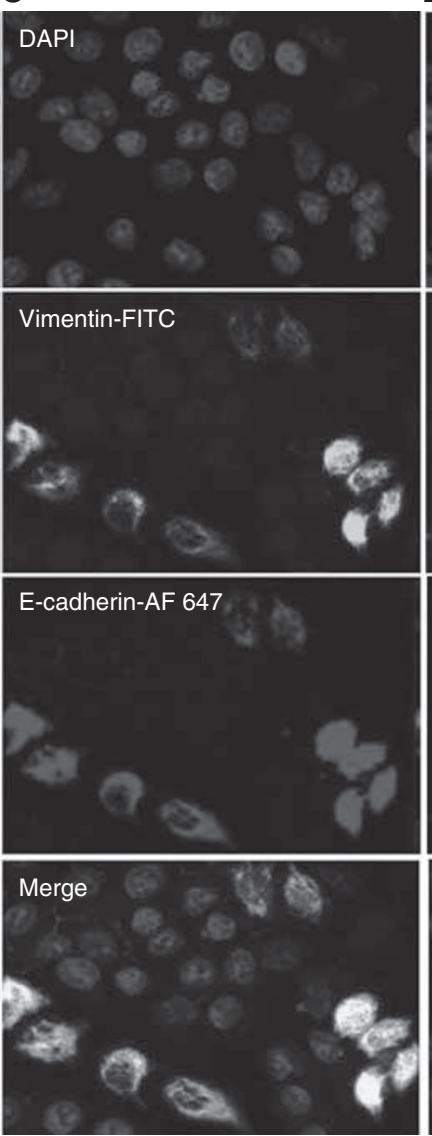

NS-398
D
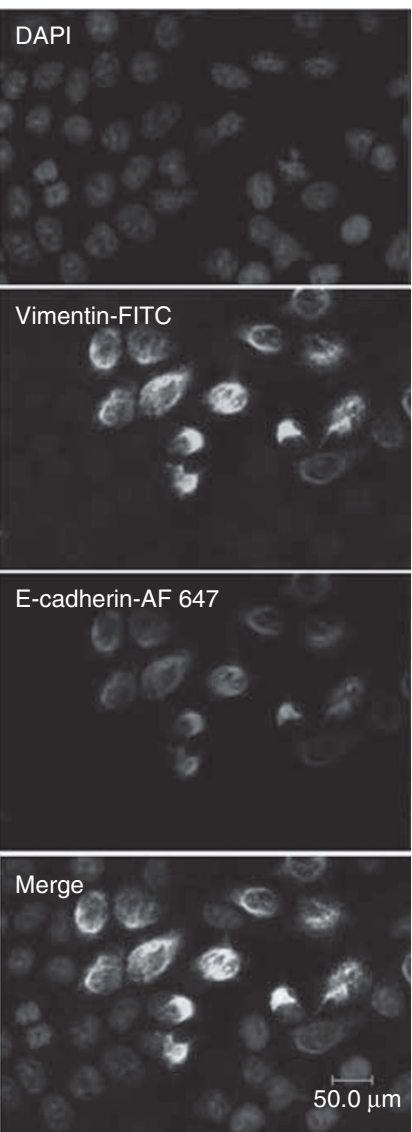

Control

Figure 4 Etodolac and celecoxib but not NS-398 induced the mesenchymal-to-epithelial transition type changes in T24 cell lines. Immunofluorescence staining for DAPI stained nuclei blue, E-cadherin-Alexa Flour 647 (red) and vimentin-FITC (green) in T24 cell lines were evaluated by confocal laser microscopy. Vimentin staining was observed in cytoskeletal lesion of control and NS-398-treated cells (C, D), but not in that of etodolac- and celecoxibtreated cells $(\mathbf{A}, \mathbf{B})$. E-cadherin expressions were observed in cell surfaces of etodolac- and celecoxib-treated cells $(\mathbf{A}$, B). Although control and NS-398-treated cells showed the mesenchymal features of cell appearance with losing cell-cell contact and an elongated phenotype (C, D), etodolac- and celecoxib-treated cells showed the characteristic 'cobblestone' appearance of epithelial cells $(\mathbf{A}, \mathbf{D})$. Scale bar, $50 \mu \mathrm{m}$. The colour reproduction of this figure is available at the British Journal of Cancer online.

$P<0.0001$, respectively) and celecoxib group with control group $(P=0.024)$. We observed the TUNEL-positive cells in the Cox-2 inhibitor treatment groups, but few were observed in the control group (Figure 7C), suggesting that Cox-2 inhibitors could induce cell apoptosis in T24 tumours in vivo.

\section{DISCUSSION}

In our in vitro study, both $10^{-4}$ and $10^{-5} \mathrm{M}$ of celecoxib significantly inhibited the cell growth of all the three bladder cancer cell lines, but $10^{-5} \mathrm{M}$ of etodolac or NS-398 significantly inhibited only T24 or 5637 cell line. These finding suggest that celecoxib had the strongest anti-tumour effect in bladder cancer cell lines. However, the interpretation of in vitro studies for an anti-tumour effect of Cox-2 inhibitors is complicated with regard to the drug concentration. Previous studies reported that much higher concentrations of celecoxib than those attainable in the serum concentration at the approved clinical dosage were required to inhibit cell growth of human bladder cancer cells (Ferrandina et al, 2003; Patel et al, 2005). Celecoxib and etodolac are commercially available in many countries, and both drugs are commonly administered with a dosage of $200 \mathrm{mg}$ two or three times a day. However, the maximum plasma concentrations of celecoxib and etodolac after oral administration at this dosage in humans were $2.14 \times 10^{-6}$ and $4.25 \times 10^{-5} \mathrm{M}$ (Kuriyama et al, 1987; Williams et al, 2000). With the concentrations in our in vitro study, only $10^{-5} \mathrm{M}$ of etodolac achieved the in vitro growth inhibitory effect in T24 cells within the clinical drug concentration. However, Williams et al (2000) demonstrated that $2.3 \times 10^{-6} \mathrm{M}$ of celecoxib, which could not achieve the in vitro cell growth inhibitory effect, significantly reduced the in vivo tumour growth of HCA-7, a human colon cancer cell line, in nude mice xenografts. This discrepancy between in vitro and in vivo studies suggest the involvement of factors other than the anti-proliferative effect of Cox-2 inhibitors.

Recent studies have shown that EMT has crucial roles in not only embryonic development and tissue repair but also in the progression of carcinoma (Hugo et al, 2007; Wu and Zhou, 2008; Yang and Weinberg, 2008). EMT facilitates cell migration and invasion, induces stem cell properties, prevents apoptosis and senescence, and contributes to immunosuppression. Thus, EMT is involved in many critical events during tumour metastasis and progression. In this study, we examined whether Cox-2 inhibitors could induce MET, which is the reversal of EMT, in three human bladder cancer cell lines.

The loss of E-cadherin is a fundamental event in EMT and is induced by E-cadherin repressors such as SNAIL, Zeb, Slug, Twist and others (Onder et al, 2008). SNAIL binds to E-box consensus sequences in the E-cadherin promoter and tightly regulates the 
Cox-2 inhibitors and EMT in bladder cancer

A

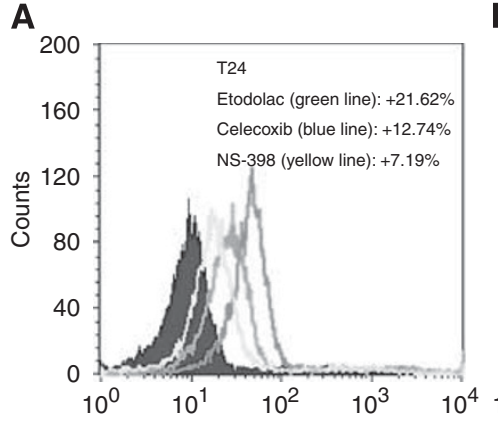

B

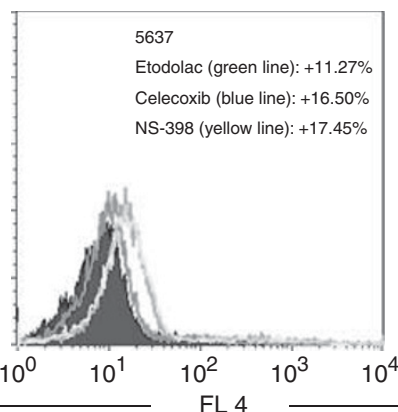

C

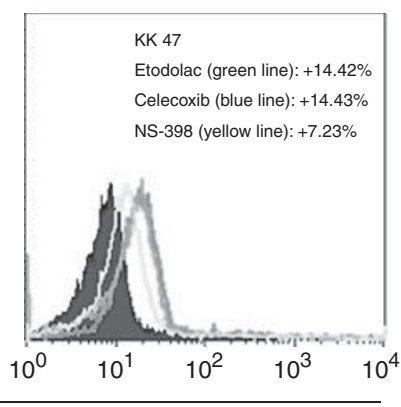

D

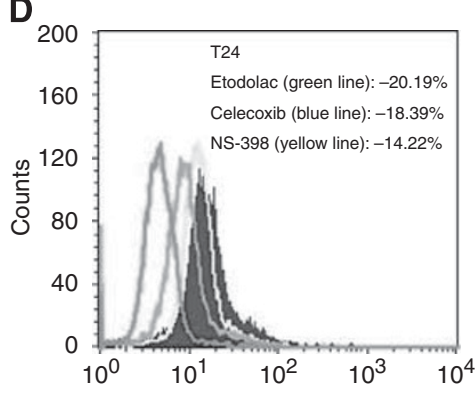

E

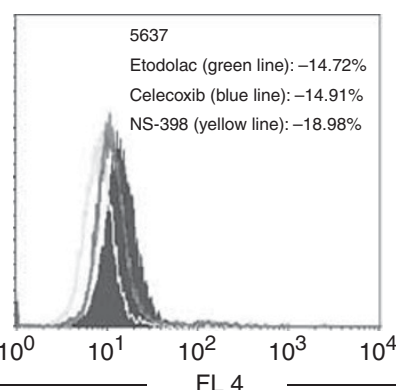

$\mathbf{F}$

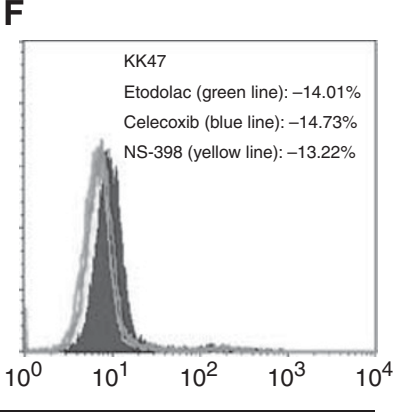

Figure 5 FCM analysis of E-cadherin $(\mathbf{A}-\mathbf{C})$ and vimentin $(\mathbf{D}-\mathbf{F})$ after treatment with DMSO as a control, etodolac, celecoxib and NS 398 at $10^{5} \mathrm{M}$ on T24, KK47 and NS398 cell lines. Results were given as the percentage of up or downregulatian of E-cadherin and vimentin. We calculated the changes in the ratio of $E$-cadherin or vimentin expressed cells: $A-B / B: A=$ marker expressed cell number with Cox-2 inhibitors, $B=$ marker expressed cell number without Cox-2 inhibitors. In the histograms, the colour lines represent staining with E-cadherin or vimentin antibody after treatment with Cox-2 inhibitors, and the purple histogram represents the control without Cox-2 inhibitors. The colour reproduction of this figure is available at the British Journal of Cancer online.

A
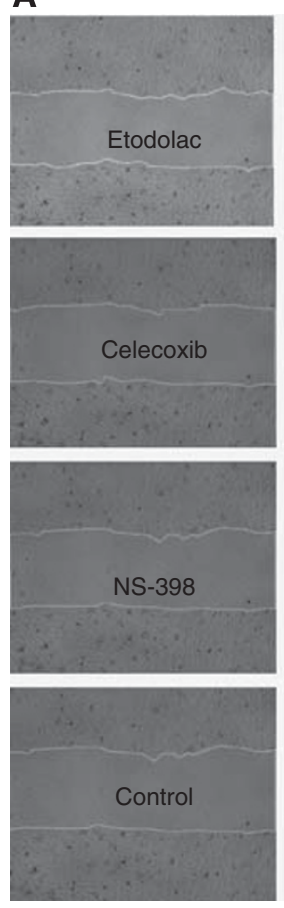

$\mathrm{Oh}$
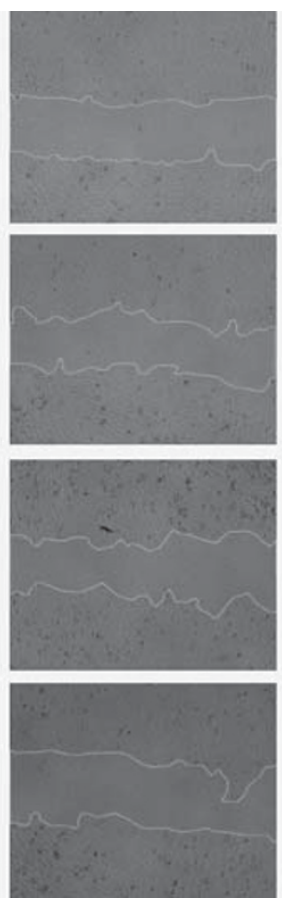

$4 \mathrm{~h}$
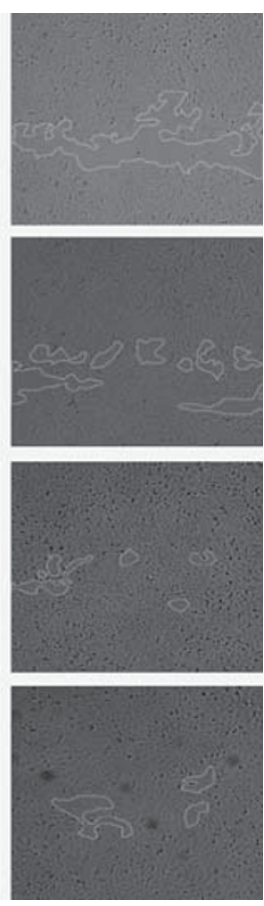

$24 \mathrm{~h}$
B

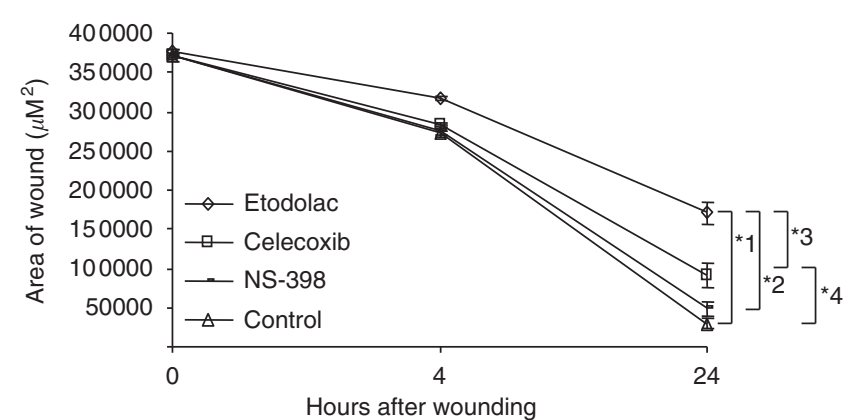

Hours after wounding

Figure 6 T24 cells were incubated with medium with Cox-2 inhibitors at $10^{-5} \mathrm{M}$ and allowed to migrate into wound area for up to $24 \mathrm{~h}$ at $37^{\circ} \mathrm{C}$. Images were acquired immediately, 0, 4 and $24 \mathrm{~h}$. Wound area without cells was calculated and then we compared the total wound area without cell of each drug (A). At $24 \mathrm{~h}$ after creating scratch, T-24 cells treated with Cox-2 inhibitors migrated slower than the control cells. The highest inhibition of cell migration was observed in the cells treated with etodolac in $24 \mathrm{~h}(\mathbf{B})$. Each point represents the triplicate average of the area without cells of each treatment drug with \pm s.e.m. bars. *I, $P<0.000$ I; *2, $P=0.0012 ; * 3, P=0.01$; *4, $P=0.002$ 

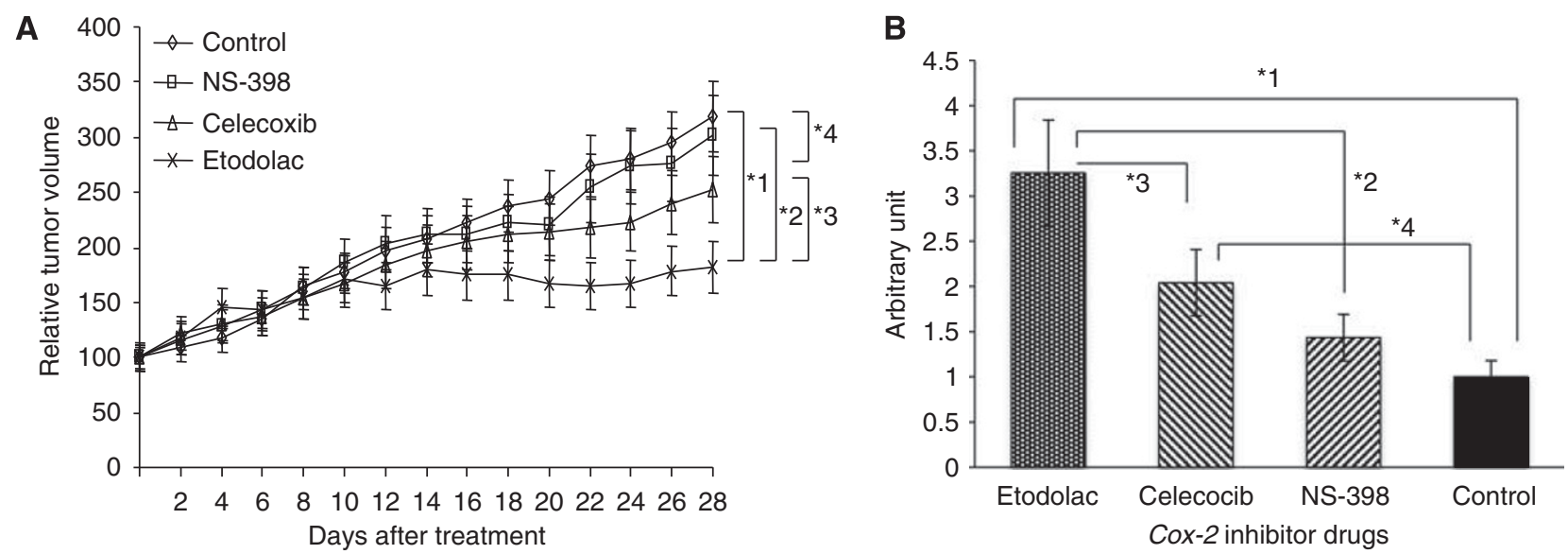

C
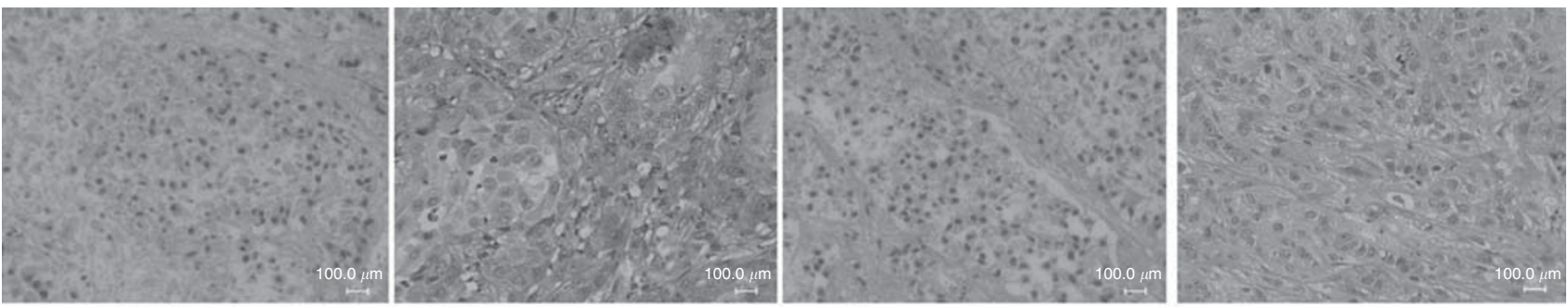

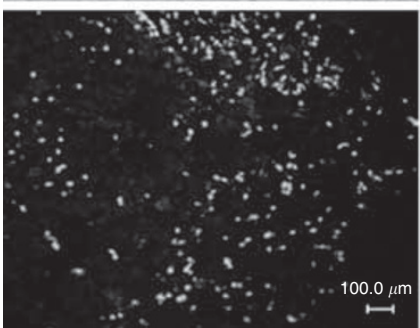

Etodolac

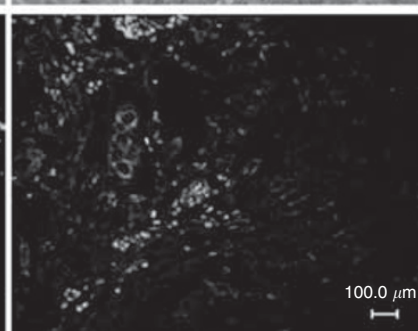

Celecoxib

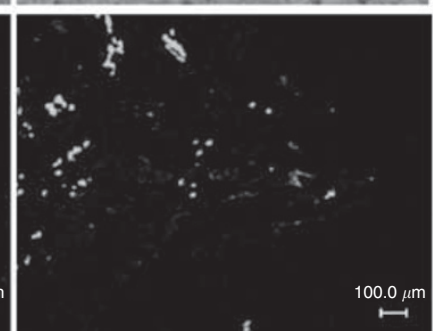

NS-398

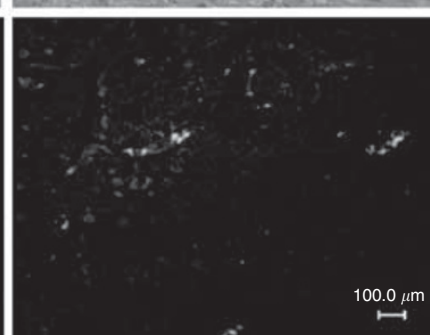

Control

Figure 7 In vivo tumour growth curve $(\mathbf{A})$ and TUNEL staining $(\mathbf{B}, \mathbf{C})$ of T24 tumour treated with Cox-2 inhibitors. (A) The daily administration of $10 \mathrm{mg} \mathrm{kg}^{-1}$ body weight per day of etodolac significantly suppressed the tumour growth at weeks 3 and 4 compared with that of the celecoxib, NS-398 and DMSO treatment group. The relative tumour volume was calculated assuming the rate of each tumour volume at day 0 to be 100 . Each point represents the average of the tumours of each treatment group, with \pm s.d. bars. *I, $P=0.031 ; * 2, P=0.05 ; * 3, P=0.04 ; * 4, P=0.002$. (B) Apoptotic cells detected by TUNEL staining of tumour tissues. Apoptotic index of each group was expressed as its relative proportion to the untreated control. Each point represents the average of the tumours of each treatment group, with \pm s.d. bars. Magnification $\times 80$. Statistical significance was evaluated by Student's $t$-test. The difference in apoptotic index among some treatment group and control reached statistical significance $(* 1, P<0.000 I ; * 2, P=0.00 I ; * 3, P=0.03$; $* 4, P=0.024$, respectively). (C) The TUNEL-positive cells in the Cox-2 inhibitor treatment groups, etodolac, celecoxib and NS-398 but it was minimal in those in the control group.

E-cadherin expression at the transcriptional level (Cano et al, 2000). Among the three human bladder cancer cell lines, T24, 5637 and KK47, originated from tumours of three different histological grades: III, II and I (Bubenik et al, 1973; Kotoh et al, 1997), T24 showed the strongest EMT feature, characterised by loss of mRNA expressions of E-cadherin and cytokeratin, and overexpressions of mRNA of vimentin, SNAIL, Slug, Twist and Zeb1 (Figure 2). T24 cells also expressed the highest level of Cox-2 mRNA and were originally isolated from the invasive grade III TCC of the urinary bladder. The strong inverse correlations between the expressions of E-cadherin and E-cadherin repressors, also called EMT transcriptional factors, SNAIL, Slug, Twist and Zeb1, were confirmed in the quantitative PCR study, which also showed that the highest E-cadherin expression and the lowest expressions of EMT transcriptional factors in 5637 cells (Figure 2). Interestingly, each of the three Cox-2 inhibitors at $10^{-5} \mathrm{M}$ showed the highest induction of E-cadherin and suppression of the most of EMT transcriptional factors across all cell lines. Etodolac most strongly induced the expression of E-cadherin and suppressed the expression of SNAIL, Slug, Twist and Zeb1, in T24, NS-398 most strongly induced E-cadherin and suppressed the SNAIL, Slug, Twist and Zeb1, in 5637, and celecoxib most strongly induced the expression of E-cadherin and suppressed the expression of SNAIL, Slug and Twist, in KK47 (Figure 3A and C).

We also examined the cell surface expression of E-cadherin, as an epithelial marker, and vimentin, as a mesenchymal marker, in the three bladder cancer cell lines treated with the three Cox-2 inhibitors using the FCM. Consistent with the quantitative PCR study for EMT molecular signal markers, the E-cadherin and SNAIL genes, etodolac most strongly induced E-cadherin expression and reduced vimentin expression on the cell surface of T24, NS-398 most strongly induced E-cadherin and reduced vimentin on 5637, and celecoxib most strongly induced E-cadherin and reduced vimentin on KK47 (Figure 4). These drug affinities to each cell line should be further investigated to elucidate the mechanism of action for anti-tumour activity of Cox-2 inhibitors. Previously, Kuriyama et al (1987) measured the IC50 values for Cox-1 and Cox-2 of different Cox-2 inhibitors by using human peripheral 
monocytes. Kato et al (2001) reported that the respective mean IC50 values for Cox-1 and Cox-2 IC50 $\left(10^{-6} \mathrm{M}\right)$, and the Cox-1/Cox-2 ratio of each drug were as follows: celecoxib, 82, $6.8,12$; etodolac, $>100,53,>1.9$; NS-398, 125, 5.6, 22. Indeed etodolac has the lowest Cox-2 selectivity and highest Cox-2 IC50 $\left(5.3 \times 10^{-5} \mathrm{M}\right)$ among the three COX-2 inhibitors in their experiments. From these data, Cox-2 inhibition might not directly contribute to the in vivo tumour growth inhibitory effect and reversal EMT effect in human bladder cancer cells that we used here.

Recent investigations have suggested that EMT has essential roles in tumour invasion and metastasis, and which are among the most characteristic features of aggressive cancer cells (Sabbah et al, 2008; Thiery, 2009). The mesenchymal properties of EMT are reported to reduce adhesion and enhance migration of cancer cells, and to promote both the tumour invasion and metastasis (Thiery, 2002). Our immunofluorescence staining study (Figure 5) revealed that etodolac and celecoxib enhanced the expression of E-cadherin in intracellular membrane, suppressed the expression of vimentin in cytoskeketal lesion, and induced the characteristic 'cobblestone' appearance of epithelial cells (Figure 5A and B), but NS-398 did not induce these changes in T24 cells (Figure 5C). We also evaluated the effect of the three Cox-2 inhibitors on the cell migration of the most invasive T24 cell line, using the wound healing assay, and found that etodolac at $10^{-5} \mathrm{M}$ most strongly inhibited the cell migration of T24 compared with the other Cox-2 inhibitors (Figure 6). In the invasive T24 cell line, etodolac markedly reduced SNAIL mRNA expression and the vimentin cell surface expression, whereas it induced E-cadherin mRNA expression and E-cadherin cell surface expression. It also strongly inhibited cell migration. Taken together, these data suggest that etodolac might have a reversal effect on EMT in the T24 cell line. In the present in vivo study, etodolac also showed the highest tumour growth inhibitory effect in T24 xenograft tumour model compared with the other Cox-2 inhibitors (Figure 7A). In addition, we observed the significant increase of the cell apoptosis in the tumour tissues treated with etodolac and celecoxib compared with control, and etodolac compared with the other groups (Figure 7B and D). Furthermore, the dose (10 $\mathrm{mg} \mathrm{kg}^{-1}$ body weight per day) of the three Cox-2 inhibitors used in this in vivo experiment was close to that commonly used in clinical applications for analgesia 400-600 mg per day (Lin et al, 2006; Okamoto et al, 2008).

Although selective Cox-2 inhibitors have significantly fewer gastrointestinal side-effects compared with traditional non-steroidal anti-inflammatory drugs, many reports have been published on the potential cardiovascular and thromboembolic complications of higher dose of celecoxib (Solomon et al, 2005, 2006). Thus, it is critical to achieve an anti-tumour effect with an acceptable dose of Cox- 2 inhibitors. In the present study, we demonstrated that the standard clinical drug concentrations of etodolac could induce both in vitro and in vivo growth inhibitory effects in the invasive human bladder cancer cell line, T24, and that this anti-tumour effect might be mediated, at least in part, by reversing EMT.

In conclusion, we demonstrated that etodolac at a dose comparable with that used clinically could induce in vitro and in vivo anti-tumour effects and a reversal effect on the EMT in the invasive bladder cancer cell line T24. The reversal effect on the EMT was assumed based on the observation that etodolac markedly reduced the SNAIL mRNA expression and the vimentin cell surface expression and induced the E-cadherin mRNA expression and the E-cadherin cell surface expression, and also strongly inhibited cell migration in T24 cells. Our findings suggest that etodolac is a good candidate for an anti-tumour or chemopreventive reagent for high-grade bladder cancer that has a high risk of recurrence and progression to invasion.

\section{REFERENCES}

Ahmed SA, Gogal Jr RM, Walsh JE (1994) A new rapid and simple nonradioactive assay to monitor and determine the proliferation of lymphocytes: an alternative to [3H]thymidine incorporation assay. J Immunol Methods 170: 211-224

Birchmeier W, Behrens J (1994) Cadherin expression in carcinomas: role in the formation of cell junctions and the prevention of invasiveness. Biochim Biophys Acta 1198: 11-26

Bubenik J, Baresova M, Viklicky V, Jakoubkova J, Sainerova H, Donner J (1973) Established cell line of urinary bladder carcinoma (T24) containing tumour-specific antigen. Int J Cancer 11: 765-773

Cano A, Perez-Moreno MA, Rodrigo I, Locascio A, Blanco MJ, del Barrio MG, Portillo F, Nieto MA (2000) The transcription factor snail controls epithelial-mesenchymal transitions by repressing E-cadherin expression. Nat Cell Biol 2: 76-83

Chaffer CL, Brennan JP, Slavin JL, Blick T, Thompson EW, Williams ED (2006) Mesenchymal-to-epithelial transition facilitates bladder cancer metastasis: role of fibroblast growth factor receptor-2. Cancer Res 66: $11271-11278$

Dhawan D, Craig BA, Cheng L, Snyder PW, Mohammed SI, Stewart JC, Zheng R, Loman RA, Foster RS, Knapp DW (2010) Effects of short-term celecoxib treatment in patients with invasive transitional cell carcinoma of the urinary bladder. Mol Cancer Ther 9: $1371-1377$

Ferrandina G, Ranelletti FO, Legge F, Lauriola L, Salutari V, Gessi M, Testa AC, Werner U, Navarra P, Tringali G, Battaglia A, Scambia G (2003) Celecoxib modulates the expression of cyclooxygenase-2, ki67, apoptosis-related marker, and microvessel density in human cervical cancer: a pilot study. Clin Cancer Res 9: 4324-4331

Fogh J (1978) Cultivation, characterization, and identification of human tumor cells with emphasis on kidney, testis, and bladder tumors. Natl Cancer Inst Monogr 49: 5-9

Guarino M, Rubino B, Ballabio G (2007) The role of epithelialmesenchymal transition in cancer pathology. Pathology 39: 305-318
Guo JY, Huo HR, Zhao BS, Liu HB, Li LF, Ma YY, Guo SY, Jiang TL (2006) Cinnamaldehyde reduces IL-1beta-induced cyclooxygenase-2 activity in rat cerebral microvascular endothelial cells. Eur J Pharmacol 537: $174-180$

Hugo H, Ackland ML, Blick T, Lawrence MG, Clements JA, Williams ED, Thompson EW (2007) Epithelial-mesenchymal and mesenchymalepithelial transitions in carcinoma progression. J Cell Physiol 213: $374-383$

Imao T, Koshida K, Endo Y, Uchibayashi T, Sasaki T, Namiki M (1999) Dominant role of E-cadherin in the progression of bladder cancer. J Urol 161: $692-698$

Jemal A, Siegel R, Ward E, Murray T, Xu J, Thun MJ (2007) Cancer statistics, 2007. CA Cancer J Clin 57: 43-66

Kato M, Nishida S, Kitasato H, Sakata N, Kawai S (2001) Cyclooxygenase-1 and cyclooxygenase- 2 selectivity of non-steroidal anti-inflammatory drugs: investigation using human peripheral monocytes. J Pharm Pharmacol 53: 1679-1685

Kenney PA, Wszolek MF, Rieger-Christ KM, Neto BS, Gould JJ, Harty NJ, Mosquera JM, Zeheb R, Loda M, Darling DS, Libertino JA, Summerhayes IC (2011) Novel ZEB1 expression in bladder tumorigenesis. BJU Int 107: $656-663$

Kotoh S, Naito S, Yokomizo A, Kohno K, Kuwano M, Kumazawa J (1997) Enhanced expression of gamma-glutamylcysteine synthetase and glutathione S-transferase genes in cisplatin-resistant bladder cancer cells with multidrug resistance phenotype. J Urol 157: 1054-1058

Kuriyama K, Fujita D, Kitani T (1987) [Phase I study of RAK-591 (etodolac)]. Rinsho Iyaku 3: 419-446

Lin S, Levin L, Emodi O, Abu El-Naaj I, Peled M (2006) Etodolac versus dexamethasone effect in reduction of postoperative symptoms following surgical endodontic treatment: a double-blind study. Oral Surg Oral Med Oral Pathol Oral Radiol Endod 101: 814-817

McConkey DJ, Choi W, Marquis L, Martin F, Williams MB, Shah J, Svatek R, Das A, Adam L, Kamat A, Siefker-Radtke A, Dinney C 
(2009) Role of epithelial-to-mesenchymal transition (EMT) in drug sensitivity and metastasis in bladder cancer. Cancer Metastasis Rev 28: $335-344$

Mendez MG, Kojima S, Goldman RD (2011) Vimentin induces changes in cell shape, motility, adhesion during the epithelial to mesenchymal transition. FASEB J 24: $1838-1851$

Morgillo F, Bareschino MA, Bianco R, Tortora G, Ciardiello F (2007) Primary and acquired resistance to anti-EGFR targeted drugs in cancer therapy. Differentiation 75: 788-799

Okamoto A, Shirakawa T, Bito T, Shigemura K, Hamada K, Gotoh A, Fujisawa M, Kawabata M (2008) Etodolac, a selective cyclooxygenase-2 inhibitor, induces upregulation of E-cadherin and has antitumor effect on human bladder cancer cells in vitro and in vivo. Urology 71: 156-160

Onder TT, Gupta PB, Mani SA, Yang J, Lander ES, Weinberg RA (2008) Loss of E-cadherin promotes metastasis via multiple downstream transcriptional pathways. Cancer Res 68: 3645-3654

Parada B, Sereno J, Reis F, Teixeira-Lemos ZE, Garrido P, Pinto AF, Cunha MF, Pinto R, Mota A, Figueiredo A, Teixeira F (2009) Anti-inflammatory, anti-proliferative and antioxidant profiles of selective cyclooxygenase-2 inhibition as chemoprevention for rat bladder carcinogenesis. Cancer Biol Ther 8: 1615-1622

Pasin E, Josephson DY, Mitra AP, Cote RJ, Stein JP (2008) Superficial bladder cancer: an update on etiology, molecular development, classification, and natural history. Rev Urol 10: $31-43$

Patel MI, Subbaramaiah K, Du B, Chang M, Yang P, Newman RA, CordonCardo C, Thaler HT, Dannenberg AJ (2005) Celecoxib inhibits prostate cancer growth: evidence of a cyclooxygenase-2-independent mechanism. Clin Cancer Res 11: 1999-2007

Qin J, Yuan J, Li L, Liu H, Qin R, Qin W, Chen B, Wang H, Wu K (2009) In vitro and in vivo inhibitory effect evaluation of cyclooxygenase-2 inhibitors, antisense cyclooxygenase- $2 \mathrm{cDNA}$, and their combination on the growth of human bladder cancer cells. Biomed Pharmacother 63: $241-248$

Raftopoulou M, Etienne-Manneville S, Self A, Nicholls S, Hall A (2004) Regulation of cell migration by the $\mathrm{C} 2$ domain of the tumor suppressor PTEN. Science 303: 1179-1181
Sabbah M, Emami S, Redeuilh G, Julien S, Prevost G, Zimber A, Ouelaa R, Bracke M, De Wever O, Gespach C (2008) Molecular signature and therapeutic perspective of the epithelial-to-mesenchymal transitions in epithelial cancers. Drug Resist Updat 11: 123-151

Sanchez-Tillo E, Lazaro A, Torrent R, Cuatrecasas M, Vaquero EC, Castells A, Engel P, Postigo A (2010) ZEB1 represses E-cadherin, induces an EMT by recruiting the SWI/SNF chromatin-remodeling protein BRG1 Oncogene 29: 3490 - 3500

Shariat SF, Pahlavan S, Baseman AG, Brown RM, Green AE, Wheeler TM, Lerner SP (2001) E-cadherin expression predicts clinical outcome in carcinoma in situ of the urinary bladder. Urology 57: 60-65

Solomon SD, McMurray JJ, Pfeffer MA, Wittes J, Fowler R, Finn P, Anderson WF, Zauber A, Hawk E, Bertagnolli M (2005) Cardiovascular risk associated with celecoxib in a clinical trial for colorectal adenoma prevention. N Engl J Med 352: 1071-1080

Solomon SD, Pfeffer MA, McMurray JJ, Fowler R, Finn P, Levin B, Eagle C, Hawk E, Lechuga M, Zauber AG, Bertagnolli MM, Arber N, Wittes J (2006) Effect of celecoxib on cardiovascular events and blood pressure in two trials for the prevention of colorectal adenomas. Circulation 114: $1028-1035$

Thiery JP (2002) Epithelial-mesenchymal transitions in tumour progression. Nat Rev Cancer 2: $442-454$

Thiery JP (2009) Epithelial-mesenchymal transitions in cancer onset and progression. Bull Acad Natl Med 193: 1969-1978; discussion 1978-1979

Wiklund ED, Bramsen JB, Hulf T, Dyrskjot L, Ramanathan R, Hansen TB, Villadsen SB, Gao S, Ostenfeld MS, Borre M, Peter ME, Orntoft TF, Kjems J, Clark SJ (2011) Coordinated epigenetic repression of the miR-200 family, miR-205 in invasive bladder cancer. Int J Cancer 128: $1327-1334$

Williams CS, Watson AJ, Sheng H, Helou R, Shao J, DuBois RN (2000) Celecoxib prevents tumor growth in vivo without toxicity to normal gut: lack of correlation between in vitro and in vivo models. Cancer Res 60: 6045-6051

Wu Y, Zhou BP (2008) New insights of epithelial-mesenchymal transition in cancer metastasis. Acta Biochim Biophys Sin (Shanghai) 40: 643-650

Yang J, Weinberg RA (2008) Epithelial-mesenchymal transition: at the crossroads of development and tumor metastasis. Dev Cell 14: 818-829 